\title{
EXPOSICIÓN Y VULNERABILIDAD. UNA APROXIMACIÓN A LA FICCIÓN
}

\author{
Francisco José PÉREZ-FernándeZ \\ I.E.S. Polígono Sur
}

\begin{abstract}
Resumen: El hombre siempre ha buscado desarrollar parcelas de la realidad inexploradas. La tecnología se ha mostrado como el ámbito de inteligibilidad más presente y desarrollada en los últimos tiempos. No obstante, además de la tecnología, se muestra el lenguaje y la ficción como estructuras de comprensión de las posibilidades humanas. Rastrear la virtualidad humana desde tales estructuras es la finalidad del presente artículo; encontrar desde la vulnerabilidad y la exposición de la subjetividad, la habitabilidad de un mundo.

Palabras clave: ficción, subjetividad, habitabilidad, fenomenología.

Abstract: Man has always sought to develop plots of unexplored reality. Technology has proven to be the most actual and developed field of intelligibility in recent times. However, in addition to technology, language and fiction are shown as structures for understanding human possibilities. Tracking human potentiality from such structures is the purpose of this article, as well as finding, from the vulnerability and the exposure to subjectivity, the habitability of a world.
\end{abstract}

Keywords: fiction, subjectivity, habitability, phenomenology.

No sin cierto asombro se asiste a una petición impactante y extraordinaria en los medios de comunicación-para una persona habituada a tales medios, esto ya resulta chocante-, la visión de un industrial pretendiendo construir una plataforma en Marte para que esta sea poblada y habitada por una serie de individuos que pueden llegar para no volver; su misión es de ida, incierta vuelta. La misión de Mars-One es crear un asentamiento humano en Marte con la finalidad de explorar nuevos territorios y nuevas formas tecnológicas de vivir, incluso, supongo, considerar las modificaciones que lo humano puede sufrir en tales condiciones. La esperanza de que todo sea posible se podría traducir en que, dadas las condiciones tecnológicas pertinentes, el hombre todo lo puede alcanzar. Por otra parte, tal asentamiento también se muestra como un espacio democrático en la medida en que, en principio, cualquiera puede pedir la entrada: una selección psicológica será llevada a cabo para descubrir 
a aquellos que puedan soportar la permanencia en tal centro; recordamos que la expedición es solo de ida y no hay vuelta. Tampoco se descubre nada nuevo, no son exploradores, son integrantes de una máquina capaz de soportar las inclemencias de la atmósfera marciana. En este sentido, no se trata de una expedición, sino de mostrar las condiciones tecnológicas pertinentes para poder vivir en Marte. El individuo solo debe preocuparse de ser capaz de habitar un lugar completamente cercado del cual no se puede salir de cuerpo presente, sí de un modo virtual, a través de infinidad de cámaras que grabarán cada paso que se dé dentro del "inefable" edificio. De este modo, su medio de financiación es un reality show: entramos en un medio extremadamente contemporáneo de realidad virtual. No se sabrá si es real o ficticio en la medida en que el contacto con ellos estará siempre mediado por la imagen (se desarrollan de un modo inequívoco las dudas sobre la llegada del hombre a la luna). Ahora bien, en este experimento nos encontramos con un proceso de crear un microclima en el que el hombre puede habitar sin exponerse más que a sí mismo: un viaje solipsista hacia lo "banal" de las relaciones humanas en un espacio cerrado. Esto no debe ser mal entendido, tan solo apuntar que la pretensión de tal viaje no es encontrar nuevos mundos, sino trasladar el mundo humano hacia otros lugares. No hay nada nuevo que descubrir, al menos en el sentido en que los españoles se lanzaron hacia nuevas tierras, nuevas vidas, nuevas costumbres y nuevos hombres. En definitiva, no un nuevo modo de ver el mundo, sino, por el contrario, un ignoto asentamiento remodelando y recreando las condiciones del planeta tierra. Condicionar un lugar inhabitable para reconstruir una vida humana fuera de una atmósfera más o menos benigna. No obstante, y al margen de las posibilidades tecnológicas, si de algo nos vale este ejemplo es por atender a la necesidad de ampliar el mundo y, quizás, el conocimiento humano. Ahora bien, no quisiéramos caer en la tentación de alimentar el ámbito tecnológico; más bien, al contrario, quisiéramos atender a otras virtualidades, a aquellas que provienen del lenguaje: la necesidad de construir mundos lingüísticos donde los diversos modos de habitar humanos puedan ser puestos de manifiesto.

Desde este planteamiento, quisiéramos adentrarnos, no tanto en la capacidad de recrear un lugar habitable en un espacio inadmisible para el hombre cuanto crear atmósferas humanas en un mundo a veces inhumano o, quizás mejor, inhabitable. Para ello, intentaremos adentrarnos en las posibilidades de habitabilidad del ser humano y cuáles son las condiciones de la misma. Podríamos estar, en principio, de acuerdo con estas palabras de Sloterdijk: «Vivir en esferas significa generar la dimensión que pueda contener seres humanos» ${ }^{1}$.

Ciertamente, la constitución de la ciudad se conforma en un espacio de territorialidad donde el hombre pretende quedar a salvo y satisfacer sus

${ }^{1}$ Sloterdijk, P., Esferas, I, Siruela, Madrid, 2003, pág. 37. 
necesidades ${ }^{2}$. Pero no solo esto nos permite ser humanos en un mundo a la intemperie, sino también la capacidad de exponernos al misterio de la ruptura de los limes o, siguiendo el pensamiento de Aristóteles, la posibilidad de encontrar una vida mejor. Sobre esta idea incidiremos, ya que consideramos que este carácter de expuesto es más intenso que la capacidad de protección del ser humano, además de establecer un acercamiento a aquello que caracteriza máximamente a lo humano: la comunicación y la capacidad constitutiva del lenguaje ${ }^{3}$.

Desde esta perspectiva, sería preciso preguntarse por las condiciones de posibilidad de la habitabilidad y una existencia humana donde el lenguaje, un tiempo, un acervo de conocimiento, etc. marcan unas condiciones de vida. Desde estas se intentará mostrar la posibilidad de ampliación del campo de fenomenalidad y la extensión de lo humano en tanto humano, al margen o más allá de la tecnología — aquello que amplía el mundo humano en la naturaleza-en la búsqueda de un desarrollo máximo de ciertas categorías humanas. Podríamos asumir la problemática en categorías de Sloterdijk cuando afirma que

«el habitar en esferas no puede explicitarse pormenorizadamente mientras el ser-ahí sea comprendido sobre todo desde un supuesto impulso a la soledad. La analítica del dónde existencial exige poner entre paréntesis todas las sugestiones y estados de ánimo de soledad esencial, para cerciorarse de las estructuras profundas del ser-ahí acompañado y complementado» ${ }^{4}$.

Si bien en este planteamiento se desplaza la pregunta de las estructuras profundas de soledad, cosa que evitaremos, sí que se incidirá en aquellas estructuras del "ser ahí acompañado y complementado" y se considerará, como afirma Aristóteles, la importancia del lenguaje en el proceso de socialización del hombre, no solo como proceso de comunicación, sino también-y en estas páginas más importante—-desde su capacidad de doblar o crear realidad.

Desde la invención de la escritura, el hombre ha intentado fijar la realidad en el dibujo de los sonidos. Fijar la realidad se muestra como un intento por hacer real aquello que el viento se puede llevar, hacer desaparecer. En definitiva, mostrar una interioridad en algún lugar donde un hombre pueda llegar y mostrar su forma de estar en el mundo. También pensar tal interioridad significa enajenarse

2 De este modo, afirma Aristóteles que «la comunidad perfecta de varias aldeas es la ciudad, que tiene, por así decirlo, el extremo de toda suficiencia, y que surgió por causa de las necesidades de la vida, pero existe ahora para vivir bien» (Aristóteles, Política, Instituto de Estudios Políticos, Madrid, 1970, 1252b-1253a).

${ }_{3}$ «La razón por la cual el hombre es, más que la abeja o cualquier animal gregario, un animal social es evidente: la naturaleza, como solemos decir, no hace nada en vano, y el hombre es el único animal que tiene palabra» (Ibid., 1253a-1253b).

${ }^{4}$ Ibid., pág. 311. 
en la inmensidad 5 desde una función local suya. Así podemos estar de acuerdo con Bachelard cuando afirma que

«la inmensidad está en nosotros. Está adherida a una especie de expansión de ser que la vida reprime, que la prudencia detiene, pero que continúa en la soledad. En cuanto estamos inmóviles, estamos en otra parte; soñamos en un mundo inmenso. La inmensidad es el movimiento del hombre inmóvil. La inmensidad es uno de los caracteres dinámicos del ensueño tranquilo»'.

Para poder comprender en toda su extensión la posibilidad de la habitabilidad debemos, en primer lugar, delimitar de algún modo las lindes de tal acontecimiento. Es decir, intentaremos, aunque sea provisionalmente, definir y delimitar un concepto de realidad en el que el mundo adquiera un sentido desde y en el cual el hombre pueda habitar. Para ello tomaremos como referente el mundo de la vida cotidiana en la medida en que es este mundo desde donde nos acercamos a nuestras más primarias experiencias7. De este modo, el sujeto, en tanto ser en y para el Mundo, se halla envuelto en unas estructuras mundanas interpretadas e interpretativas que le confieren su carácter mundano-social, asî como su lugar en tal Mundo, ofreciéndole una comprensión global adecuada para su incorporación y adecuación a tal realidad. Dicha comprensión viene mediada por diversas presuposiciones que se le ofrecen al sujeto a través del acervo de conocimientos que le son predonados por sus antecesores en la historicidad de la comprensión del mundo, o en su afirmación interpretativo-predecesora ${ }^{8}$. Por lo cual hemos de decir que esos procedimientos interpretativos proporcionan el background mínimo de realidad necesario para mantener el reconocimiento del Mundo que posibilite una visión de la totalidad del mismo, común a los

${ }^{5}$ Quisiéramos destacar este concepto en el pensamiento de Bachelard porque destaca ciertos caracteres de la experiencia humana. Así dice Bachelard: «La inmensidad es, podría decirse, una categoría filosófica del ensueño (...), el ensueño pone al soñador fuera del mundo próximo, ante un mundo que lleva el signo de un infinito» (Bachelard, G., La poética del espacio, F.C.E., Buenos Aires, 1991, pág. 220).

${ }^{6}$ Ibid., pág. 221.

7 "Mundo de la vida cotidiana" significará el Mundo intersubjetivo que existía mucho antes de nuestro nacimiento, experimentado e interpretado por Otros, nuestros predecesores, como un Mundo organizado. Ahora está dado a nuestra experiencia e interpretación. Toda interpretación de este Mundo se basa en un acervo de experiencias anteriores de él, nuestras propias experiencias y las que nos han transmitido nuestros padres y maestros, que funcionan como un esquema de referencia en la forma de "conocimiento a mano"» (Schütz, A., Problema de la realidad social, Amorrortu, Buenos Aires, 1974, pág. 198).

8 Así pues, podrá decirnos Gadamer, H-G., en Verdad y Método (Sígueme, Salamanca, 1984, pág. 350), que «nos encontramos siempre en tradiciones, y éste nuestro estar dentro de ellas no es un comportamiento objetivador que pensara como extraño o ajeno lo que dice la tradición; ésta es siempre más bien algo propio, ejemplar o aborrecible, es un reconocerse en el que para nuestro juicio bistórico posterior no se aprecia apenas conocimiento, sino un imperceptible ir transformándose al paso de la misma tradición». 
interactuantes. Así pues, será desde este background mínimo de realidad desde donde las experiencias nuevas podrán ser reconocidas, esto es, desde donde, dado su carácter global, podrán ser asumidas en el acervo de experiencias previas. Se habrá de reconocer con Husserl que

«el ser del mundo en su totalidad es lo sobreentendido, de lo que nunca se duda y no ha sido adquirido primero mediante la actividad judicativa, sino que ya es presupuesto para todo juicio. Conciencia del mundo es conciencia en el modo de la certeza de creencia y no algo adquirido mediante un acto de asentar el ser [Seinssetzung], que se presenta ex profeso en el contexto de la vida, un acto de aprehensión como existente [als daseiend] o tal vez del juicio existencial predicativon?.

Concluiremos, pues, que es desde el carácter interior-anónimo de estos presupuestos como el mundo se hace disponible y habitual y, por tanto, se configura para el sujeto como un lugar familiar (oikós) y dispuesto para la proyección de la ejecución. Todo ello en la medida en que la habitualidad que autoriza los presupuestos del acervo de conocimiento permite a la acción ser automática o inercial y, en la mayor parte de los casos, no-consciente, en virtud de que la finalidad propuesta por el esquema de referencia como "conocimiento a la mano" sea la de señalar y marcar diversos objetos y personas para su más fácil reconocimiento. Han ordenado y organizado el mundo bajo un conjunto de marcas y orientaciones para un mejor encuentro con la realidad, en la medida en que las estructuras organizativas que forman parte del conocimiento anónimo impelen al sujeto a entender el mundo de una determinada manera y no otra. Ahora bien, en ningún caso como un conjunto cerrado de experiencias, sino, al contrario, como un horizonte abierto a una infinidad de experiencias nuevas, aunque, antes bien, teledirigidas ${ }^{10}$.

Ahora bien, debemos partir de la certeza de que el mundo de la vida cotidiana es un mundo interpretado, sin que su interpretación deba ser entendida como individual, sino, más bien, como una experiencia colectiva que recorre el pasado y el presente, además de proponer las líneas a seguir en el futuro (horizonte). En este sentido, este acervo de conocimientos que interpretan el Mundo y proporcionan una visión del mismo se podría denominar tradición. Esto es, un conocimiento previo que, dado su carácter anterior, pre-organiza y pre-constituye el Mundo convocando con ello un espacio común de comunicación y conocimiento donde

9 Husserl, E., Experiencia y juicio, UNAM, México, 1980, pág. 31.

${ }^{10}$ Esta misma idea se encuentra en Ortega y Gasset, cuando nos describe la «estructura de "nuestro" mundo» como una correlación de "campos pragmáticos" en los que el sujeto se halla envuelto en su discurrir vital. Con ello, nos dice que «se nos ha complicado un poco más la estructura del mundo, pues ahora tenemos tres planos o términos en él: en primer término la cosa que nos ocupa, en segundo el horizonte a la vista, dentro del cual aparece, y en tercer término el más allá latente "ahora" " (Ortega y Gasset, J., El hombre y la gente, Alianza/Revista de Occidente, Madrid, 1988, pág. 72). 
los diversos sujetos pueden interactuar entre sí y con el Mundo ${ }^{11}$. La tradición, pues, en tanto conocimiento previo y anónimo, nos ofrece una visión del Mundo que nos ayuda a actuar y realizarnos en él, además de proporcionar formas de estar en la realidad. Por consiguiente, diremos que la tradición se constituye, de alguna forma, en un arcaico abstracto que dispone y ordena nuestra visión del Mundo, ocultando bajo su oscuro manto al sujeto y al objeto, llevándolos en su anonimato por los caminos trazados por ella ${ }^{12}$. De este modo, la fuerza de la tradición y nuestra visión del mundo vienen, también, encauzadas por el lenguaje que, según Gadamer,

«no es solo una de las dotaciones de que está pertrechado el hombre tal como está en el Mundo, sino que en él se basa y se representa el que los hombres simplemente tengan Mundo. Para el hombre, el Mundo está ahí como mundo, en una forma bajo la cual no tiene existencia para ningún otro ser vivo puesto en él. Y esta existencia del Mundo está constituida lingüísticamente» ${ }^{13}$.

Desde esta perspectiva, pues, el lenguaje no se ha de entender solamente como medio de comprensión y definición del Mundo, sino también, y quizás en mayor medida, como un medio de actuación y comunicación sobre y entre los interactuantes en las relaciones sociales marcadas ya por el mismo lenguaje y la tradición. Así pues, diremos que el lenguaje cotidiano viene enmarcado en su propia contextualización mundana, es decir, pertenece esencialmente al ámbito del ejecutar en la medida en que da la palabra a sus propias presuposiciones. El lenguaje, por tanto, es un modo de hacer y comunicar cosas, no solo un medio para (meramente) describir y definir, ya que las estructuras de (mera) información vienen ya presupuestas y marcadas. Con esto se quiere alumbrar que una de las funciones primordiales del lenguaje de la vida cotidiana no es tanto representar y describir una realidad, en la medida en que ésta venga configurada por la conjunción antes nombrada entre tradición y lenguaje, cuanto la de crear unas relaciones comunicativas de interacción entre los sujetos mundanos que

11 Habermas, J., Teoría de la acción comunicativa. Racionalidad de la acción y racionalización social, Taurus, Madrid, 1988, pág. 104: «El mundo de la vida acumula el trabajo de la interpretación realizado por las generaciones pasadas; es el contrapeso conservador contra el riesgo de disentimiento que comporta todo proceso de entendimiento que esté en curso. Por tanto, e inevitablemente, todo disenso implica un consenso (previo)».

12 En este sentido, Merleau-Ponty revela el carácter pre-dado de la tradición, así como su dominio de nuestra visión del mundo y de nuestra actuación sobre él: «El nivel primordial está en el horizonte de todas nuestras percepciones, pero de un horizonte que, por principio, nunca puede ser alcanzado y tematizado en una percepción expresa. (...); que mi historia sea la secuencia de una prehistoria de la que aquella utiliza los resultados adquiridos, mi existencia personal, la continuación de una tradición pre-personal» (Merleau-Ponty, M., Fenomenología de la percepción, Península, Barcelona, págs. 268-69).

13 Gadamer, H-G., Verdad y método, pág. 531. Para este autor, «la tradición no es un simple acontecer que pudiera conocerse o dominarse por la experiencia, sino que es lenguaje, esto es, habla por si mismo como lo hace un tú. El tú no es objeto sino que se comporta con respecto a "objetos"» (ibid. Pág. 434). 
les permitan actuar en el Mundo según el sentido pragmático que los orienta. En suma, bajo el manto de la tradición lingüística se hallan involucrados, incluso reactiva o contradictoriamente, los modos de vida y toda experiencia histórica mundana natural vital de cualquier sujeto que comparta en alguna medida dicha tradición. En este sentido, podemos decir con Gadamer, que «en verdad no es la historia la que nos pertenece, somos nosotros lo que pertenecemos a ella» ${ }^{14}$, o que «la comprensión misma debe ser considerada menos como una acción de la subjetividad que como un desplazarse uno mismo bacia un acontecer de la tradición» ${ }^{15}$.

La realidad del mundo de la vida cotidiana se carga de sentido y significación, mostrando al hombre como un "ser en el mundo", curándose en el trato con los útiles. La realidad se torna en un ámbito de sentido donde se manipulan objetos y donde las relaciones se encuentran perfectamente enmarcadas en la disponibilidad de los papeles sociales y en el reconocimiento mutuo promovido por una tradición y lenguaje común. Tal estructura de la realidad configura un mundo perfectamente organizado donde todo tiene una significación reconocida y reconocible y donde el sujeto se muestra seguro desde una interioridad centrada en la seguridad de tal mundo, conformado desde un tiempo propio, la tradición $\mathrm{y}$ un espacio dominado por una técnica que permite manipular el entorno que le rodea. De este modo, afirma Sloterdijk que «Mundo remite a todo lo que puede ser contenido por una forma o por una frontera conocida. Lo podriamos designar también, adecuadamente, como un contexto autógeno» ${ }^{16}$, más aún, completo desde una virtualidad con la suficiente potencia para asumir nuevos elementos que, tornándose indisponibles, son asumidos con una ampliación o reconsideración de sentido.

En este sentido, podría interpretarse el ser-ahí heideggeriano desde la creación de un mundo donde el hombre se muestre como dueño y pastor de una facticidad mundana en la que poder vivir. Alguien adherido a tal facticidad, involucrado en ella y movido por la vorágine de un mundo lleno de posibilidades que desarrollar. En tales posibilidades es donde se desarrolla el tiempo de lo humano, un tiempo de espera y de transformación de sentido de mundo. «El mundo-afirma Blumenberg-en vías de convertirse en vivencia le reclama a la vida el precio de su tiempo-de todo su tiempo, de más tiempo del que tiene-. Y según la amplitud de la vivencia tenida del mundo, también más tiempo cada vez. El mundo se jacta ante la vida del tiempo que se toma de mundos a mundos, y que él tiene» ${ }^{17}$.

De algún modo, la realidad se torna en mundo conformado como un lugar con sentido, donde el hombre ha afirmado su posición y su lugar, donde ha encontrado un plexo de útiles haciéndole su vida más fácil. También maneras

14 Ibid., pág. 344.

15 Ibid., pág. 363.

16 Sloterdijk, P., Esferas II, Siruela, Madrid, 2004, pág. 176.

17 Blumenberg, H., Tiempo de vida, tiempo de mundo, Pre-Textos, Valencia, 2007, pág. 26. 
de organizarse para usar mejor los elementos y sacarle un mayor rendimiento. Incluso ha distribuido sus relaciones con la trascendencia alejándole de sus mayores temores. Todo ello dirigido por la búsqueda y donación de un sentido a una vida caduca, mortecina y temerosa de lo desconocido, de todo lo que queda más allá y no puede ser controlado.

Luchar contra la incertidumbre y contra todo aquello que pudiera socavar la tranquilidad, la normalidad y sosiego de nuestra vida cotidiana, es lo que se pretende en la donación de sentido. Por tanto, habitar se muestra como una lucha contra la necesidad, al tiempo que se abre a una posibilidad de apertura hacia otras realidades donde el hombre pretende poner como referencia su acción y la mostración de otras posibilidades humanas. Lo humano se conforma en torno a la ciudad, la muralla, el interior se transforma en un caparazón desde el que ampliar el círculo salvador. En el interior se constituye aquello que puede salvar y ampliar el círculo: el lenguaje. Este tiene la capacidad de recrear la exterioridad dentro de la interioridad y transformar, por tanto, la misma. El lenguaje pareciera girar en torno a sí mismo para asumir continuamente la exterioridad, ampliar el ámbito de la interioridad. Trascender la necesidad. Esta es la idea que se pretenderá defender en estas líneas; un concepto de trascendencia que abra siempre la condiciones de posibilidad de una vida humana.

Toda cuestión de habitabilidad es una cuestión epidérmica, es decir, traza una línea desde la cual pensar un exterior y un interior; por tanto, una relación: proteger y exponer. La relación se establecería, pues, entre una protección y una exposición. Donde se ponga el acento es lo relevante para el ser humano, para su relación con el mundo y para el propio conocimiento de sí mismo.

De la realidad necesaria a la posibilidad de un lugar mejor, de la posibilidad a la realidad: distanciamiento y evasión del uno mismo. Este cambio de actitud abre el conocimiento a un mundo que lejos de estar reducido a la actualidad de su presente, muestra la riqueza del contacto con la subjetividad humana, desde la cual se manifiesta como un contenido que puede ser sometido a un proceso de variaciones a través de las cuales se instala la posibilidad además de la presunción de una libertad y sentido que abre el ámbito de lo mundano hacia el ámbito de lo posible-mundano, gracias a «un fuego, un vuelo, un espiritu constructor y la utopia consciente que no teme la realidad, pero que la trata mejor como problema y ficción» ${ }^{18}$.

Así pues, si atendemos a las palabras de Musil, la realidad adquiere, a través de la actitud estética, un carácter hermético que permite al sujeto neutralizar la multiplicidad de actitudes que el hombre desarrolla en su existir, transformando y desconectando el mundo a través de un signo que ya no es indicativo solo y exclusivamente de una referencia, sino que también atiende a la multiplicidad de connotaciones que tal referencia adquiere en su vinculación con una subjetividad

18 Musil, R., El hombre sin atributos, Seix Barral, Barcelona, 1983, pág. 20. Aunque, como revela más adelante Musil, es «la realidad la que despierta las posibilidades» (ibid., pág. 21). 
donadora de significación y con su campo de vivencias. Dicha transformación significativa es lo que permite al hombre ampliar la multifuncionalidad del existir humano, abandonando la facticidad mundana y la necesidad de transformar el mundo a través de la ejecución de acciones sobre él. Por tanto, se ha de inferir que la modificación actitudinal (modificación de neutralidad) permite la experiencia estética en su distanciamiento del mundo y ofrece la posibilidad de asumir en el marco de tal actitud, la multiplicidad de funciones-en la terminología de Mukarovsky_que el hombre desarrolla en su devenir existencial.

Por todo ello, el sentido ofrecido por la experiencia estética permite la apertura de horizontes que llevaría a una concepción de la realidad como múltiple. Dicha multiplicidad se nos ofrece a través del sentido de posibilidad definido más arriba, por la pluma de Musil, al igual que no dar más importancia a lo que es que a lo que no es nos sitúa de lleno en el ámbito de la fantasía como el hogar de la inexistencia en la medida en que alberga posibilidades no cumplidas que, aun fluctuando en la realidad, no se hacen presentes si no es a través de una intención significativa que las ponga en juego, revelando de este modo una continuidad indefinida de la realidad hacia ámbitos que trascienden la facticidad del cumplimiento y establecen un orden de pertenencia en el que una vida-que-experiencia-mundo-receptora pueda desplegar sus pertenencias. De este modo, la posibilidad de sobrepasar los contenidos constitutivos del mundo de la experiencia cotidiana abre modificaciones de tales contenidos: no parece otra la experiencia de Gregorio Samsa al despertar una mañana. Así pues, sería acertado decir que la modificación de tales contenidos de experiencia se muestra desde cierta indisponibilidad en los acontecimientos que estaban marcados en el reino de las evidencias originarias ${ }^{19}$. $\mathrm{El}$ acontecimiento que torna indisponible tales evidencias retrotrae al sujeto mundano al estilo cognoscitivo que domina la actitud natural haciendo evidente su estructuración, y esta retrotracción reflexiva es la que hace posible desvelar los límites de dicho estilo cognoscitivo. Esta indisponibilidad ha de ser radical, esto es, debe atentar contra los contenidos experienciales del mundo natural, así como la estructura de la experiencia que, alterada, transforma el mundo de las cosas en signo. Tal desplazamiento abre una cesura que desliza la presencia pragmática de la cosa hacia la ausencia sígnica, permitiendo la alteración y experimentación de las experiencias humanas. Esta cesura permite abrir el ámbito de la realidad cotidiana hacia otra realidad constituida desde la significación y el sentido. Así pues, se ha de recordar la aseveración de Schütz de que la realidad no la conforma la estructura ontológica de los objetos, sino el sentido que nosotros donemos a la experiencia. El sentido trasciende la realidad desde la desconexión y distanciamiento a los que se someten el mundo de la vida cotidiana y sus estructuras de constitución. Tal desconexión y distanciamiento es lo que permite a Schütz establecer una primera visión de la multiplicidad de realidades abiertas desde la noción de sentido

19 Husserl, E., Problemas fundamentales de la fenomenología, Alianza, Madrid, 1994, pág. 72. 
como mediación que interrumpe las estructuras pragmáticas y consuetudinarias de la vida cotidiana y que permite, por tanto, definir los ámbitos finitos de sentido como un determinado conjunto de nuestras experiencias, si todas ellas muestran un estilo cognoscitivo específico y son-con respecto a este estilo-no solo coherentes en sí mismas, sino también compatibles unas con otras. Ahora bien, cómo definir una realidad lo suficientemente abarcadora que permita transitar por todas sus modificaciones y qué lugar ocupe en las relaciones que se establecen entre las mismas, es un problema que se deberá plantear a fin de poder instalar en tal realidad una subjetividad que transite por ella y habite sus modificaciones, incluso los intersticios abiertos por ellas.

Se ha observado que el signo proporciona la posibilidad objetiva de transcurrir por diversos mundos o realidades y, que dicho trasiego, produce en la subjetividad diferentes estados de experiencia. Lo sígnico ofrece una apertura en la experiencia de horizontes a través de las significaciones que arrastra y conduce, pero también traza las fronteras ${ }^{20}$ de dicha experiencia en la interconexión de las realidades que aclara y declara, así como la posibilidad de traspasarla accediendo a otras. Por otra parte, es dicha posibilidad transgresiva la que permite y constituye la propia estructura del texto literario en la medida en que la ficción, en tanto ámbito distinto del que llamamos real, somete a este a una serie de variaciones donde se despliegan sus estructuras de sentido y significación, recreando a través de la fantasía, en tanto actividad de la imaginación, mundos posibles. En este sentido, la fantasía requiere del lenguaje para crear y representar otras realidades y es, por tanto, en la intención significativa expresada en dicho lenguaje donde adquiere su status ontológico en la medida en que como afirma Benedetti

«la realidad es, en cierto sentido, fundación de la palabra, pero a su vez ésta (tal como sostiene Carlos Fuentes al hablar de Carpentier) es "fundación del artificio". La realidad condiciona el ánimo, y éste, al generar la palabra, expurga la realidad; pero la expurga modificándola, haciéndola más brutal o más etérea, menos rampante o más soterrada, o sea imaginándola, y convirtiéndola, al imaginarla, en otra realidad que es artificion' 21 .

Así pues, el lenguaje, como expresión de una intención y cumplimentación significativas, se constituye ya no solo como un elemento mediador entre la fantasía y los mundos creados por ella, sino que también muestra los diversos mundos como lenguajes a través de los cuales discurren la experiencia del autor

${ }^{20}$ Hemos elegido el término frontera en vez de límite, asumiendo la distinción propuesta por Cencillo Ramírez en su obra El hombre, una noción científica, en la que afirma que «mientras que el limite puede significar un "no-va-más", un finis terrae, los contornos de un pleno frente a un vacio, la frontera implica un plus ultra, una continuación más allá de la misma donde tal vez se encierra mayor plenitud que del lado de acá» (Cencillo Ramírez, J., El hombre, noción científica, Pirámide, Madrid, 1978, pág. 545).

21 Benedetti, M., La realidad y la palabra, Destino, Barcelona, 1990, pág. 25. 
y del lector, así como la experiencia de los personajes y los acontecimientos que desde ellos se narran. «La función poética del discurso—afirma Martínez Bonatino es una función del discurso en la línea de las otras funciones, sino el fenómeno de un discurso completo que es ónticamente diverso del discurso real,22.

Desde esta perspectiva, pues, la estructura ficcional se construye desde la alteridad primera del autor y el lector en la medida en que el mundo a través del texto adquiere una autonomía significativa que debe ser recorrida por la experiencia de aquel involucrado en el mundo propuesto por el propio texto y presentado desde su corporalización experiencial. Así pues, se podrá coincidir con Iser al sostener que la especificidad del texto literario «se caracteriza por una típica oscilación entre el mundo de los objetos reales y el mundo de la experiencia del lecton ${ }^{23}$.

En este sentido, pues, la realidad, lejos de estar solo marcada por la estructura ontológica de los objetos, se halla en el sentido que el sujeto adjudica a sus experiencias y, por tanto, fundamentalmente, la dimensión de la realidad se debe a una estructura de la experiencia asumida en la interrelación con una palabra que describe, narra, construye y se involucra en una diversidad de realidades que se presenta en el silencio-pausa del verbo. De este modo, se recupera en la escritura-ficcional-la vida-que-experiencia-mundo, manifiesta de modo inmediato en el presente vivido del hablar cotidiano y en la relación cara-a-cara, marcada por un lenguaje, que en sentido indicativo nos ofrece la posibilidad de experienciar un "mundo" o, por utilizar terminología de Nelson Goodman, maneras-en-que-el-mundo-es ${ }^{24}$. El lenguaje ofrece la posibilidad de multiplicar las versiones de mundo a partir de las cuales el lector-figura indispensable en todo acto textual — ha de hacer devenir su experiencia. De este modo, la realidad literaria se convierte en un acto de comunicación interrelacional de mundos, alejándose de cualquier traducción ontológica, alzándose hacia la búsqueda de otros (mundos, personajes...) con los que reconciliarse a través de un diálogo dado en las inter-conexiones estructurales y experienciales.

Por otra parte, al igual que la estructuración del texto, al decir de Ingarden, requiere espacios vacíos abiertos a las experiencias del lector, la estructura constitucional-significativa de la ficción literaria ha de ser incompleta, o al menos, indeterminada. «De manera parecida - afirma Iser-los vacios, la asimetría fundamental entre texto y lector, son los que dan lugar a la comunicación en el proceso de lectura; la ausencia de una situación y un marco comín de referencia corresponden al "no bay nada" que motiva la interacción entre las personas» 25.

${ }^{22}$ Martínez Bonati, F., La ficción narrativa (Su lógica y ontologia), Universidad de Murcia, Murcia, 1992, pág. 21.

${ }^{23}$ Iser, W., «La estructura apelativa del texto» en Estética de la recepción, Visor, Madrid, 1989, pág. 137.

24 Goodman, N., Maneras de hacer mundos, Visor, Madrid, 1990, pág. 21.

25 Iser, W., "Interaction between text and reader" en Teorias de la Novela. Antología de textos del siglo XX, Crítica, Barcelona, 1996, pág. 249. 
Volvemos a la posibilidad de la introducción de la experiencia del lector en la pluralidad virtual del mundo textual. La comunicación y la re-creación de un mundo solo es posible en la interacción del lector en los vacíos abiertos por el texto, esto es, por la introducción de la posibilidad en el mundo recreado por el texto. Es la indeterminación textual la que permite introducir de manera estructural el concepto de posibilidad que definirá el concepto de realidad de los mundos posibles.

Por lo dicho hasta ahora, se podría afirmar que una de las estructuras constitutivas de la ficción es la alteridad como estructura primordial de la creación de una realidad distinta a la actual, además de la distancia que se abre entre el autor y el lector, permitiendo introducir la experiencia del lector a través de los espacios vacíos que la ficción narrativa deja abiertos. Atravesando dicha distancia, se presenta un sentido de posibilidad que constituye en su modo de ser el ámbito ficcional, en la medida en que dona relevancia a acontecimientos existenciales no fácticos pero que lo pudieron o pudieran ser. Es, por tanto, este sentido de posibilidad el que permite crear realidades múltiples frente a la realidad actual-fáctica o cotidiana, en la medida en que dicho sentido permite desplazar el plexo de objetos y preocupaciones que dominan y conducen el mundo actual hacia otros lugares de indeterminación, mostrando, de este modo, posibilidades que en ciertos momentos quedan oscurecidas. En este sentido, «la novela - escribe Kundera - no examina la realidad, sino la existencia. Y la existencia no es lo que ya ha ocurrido, la existencia es el campo de posibilidades humanas, todo lo que el hombre puede llegar a ser; todo aquello de que es capaz»»26. De este modo, se considera la posibilidad como un concepto que permite una multiplicación de realidades y la ampliación del mundo actual y, por tanto, constituye la capacidad de recrear mundos inexistentes, si bien a través de la suspensión de incredulidad son asumidos por los lectores como quasi-existentes. No obstante, la inexistencia es otra característica de la posibilidad, desde la cual el ámbito de la ficción ha de recrear su propio contexto y situarse en un orden de realidad a través de experiencias que recreen la posibilidad de establecer una región de pertenencia en la que, al menos de modo provisional, aquel que se acerque a sus estructuras experienciales tenga la impresión de compartir un mundo posible. En este sentido, sostiene Martínez Bonati que

«lo representado en la ficción literaria es una ficción porque se lo piensa como existente en nuestro mundo real y, a la vez, se lo sabe inexistente. Estas reflexiones, que solo insinúo aqui, apuntan al hecho de que la dualidad de la representación y lo en ella representado da lugar (hace posible) a la dualidad de lo real y lo irreal, lo existente y lo inexistente. La estructura de la representación lleva en si la posibilidad de la ficción» ${ }^{27}$.

${ }^{26}$ Kundera, M., El arte de la novela, Tusquets, Barcelona, 1987, pág. 53.

27 Martínez Bonati, F., La ficción narrativa, pág. 59. 
Es, por tanto, la posibilidad del sentido abierta a través de la vida-queexperiencia-mundo la que permite establecer realidades múltiples. Y, desde tal pluralidad, la subjetividad creadora-autora o lectora-desde sus experiencias fácticas (reales) y posibles (ficticias), admite desentrañar sentidos siempre diversos a partir de sus acontecimientos vitales. Algo similar asegura Sábato cuando dice que

«en esta vida única y limitada que tenemos, en cada instante nos vemos obligados a
elegir un solo camino entre infinitos que se nos presentan. Elegir esa posibilidad es
abandonar las otras a la nada (...) En la ficción ensayamos otros caminos, lanzando
al mundos esos personajes que parecen ser de carne y hueso, pero que apenas pertenecen
al universo de los fantasmas. Entes que realizan por nosotros, y de algún modo en
nosotros, destinos que la única vida nos vedó. La novela, concreta pero irreal, es la
forma que el hombre ha inventado para escapar a ese acorralamiento. Casi forma
tan precaria como el sueño, pero al menos más voluntariosa. Esta es una de las raíces
de la ficción»28.

De este modo, la posibilidad que surge de la nada abortada por la efectividad de la vida, abre caminos siempre nuevos que permiten la exploración de niveles de realidad y experiencias inexploradas. Y es este sentido vacío, de indeterminación, el que autoriza la recreación de realidades alternas ofreciendo un conocimiento más universal que el que brinda la propia realidad actual. La posibilidad se muestra, por tanto, como una estructura de la experiencia que enriquece y completa, en cierto modo, el discernimiento de la efectividad, proporcionando un conocimiento que se encuentra en la apertura de realidades no cumplidas pero que podrían haberse cumplido, y despliega la facticidad mundana hacia una inteligencia que no se hace cargo ya de la totalidad (hegeliana) de lo realde lo que es, no es, ni será-sino del despliegue de tal realidad, de su puesta en movimiento en la búsqueda de un sentido y su vinculación a una subjetividad constituyente ${ }^{29}$. No obstante, estas aseveraciones no deben ser entendidas como actualizaciones ficcionales de un mundo actual o natural sino, más bien, como mundos diferenciados que requieren una peculiar modalidad de la conciencia para ser experienciadas, desde la cual el contenido objetivo adquiere una

28 Sábato, E., El escritor y sus fantasmas, Seix Barral, Barcelona/Caracas/México, 1979, págs. 174-75.

29 Desde su reclusión en una cárcel, Václav Havel, en una carta a Olga, afirma que «el hombre y el mundo empiezan a existir al mismo tiempo, como dos "dimensiones" del único acto de separación, porque el mundo, o sea el mundo de los entes, no es otra cosa que el ser, o mejor dicho el ser del "no-yo", tal y como se manifiesta al-y por medio del- "yo" que se constituye. De manera que el mundo es el ser exteriorizado que se nos manifiesta y que nuestra "diferencialidad" "bace existente"; es una declaración o una expresión del ser, estructurada y definida por medio de la clase de carácter abierto o limitado-desde el punto de vista existencial, mental o sensorial-que poseemos. Por eso escribi-ya no me acuerdo si de modo suficientemente claro-que es cuando se constituye el "yo" cuando de hecho, también se constituye el mundo» (Havel, V., Cartas a Olga, Versal, Barcelona, 1990, págs.. 331-32). 
nueva relevancia y nuevas dimensiones que enriquecen al propio contenido ${ }^{30}$. Recordemos, en este sentido, la suspensión de incredulidad como modificación de la conciencia que debe realizar el lector al adentrarse en las líneas de concepción que supone cualquier texto literario. Así pues, la posibilidad no es una modalidad de la realidad sino, más bien, un estrato complementario de dicha modalidad en la medida en que abre a la misma — la realidad—hacia nuevos ámbitos; se podría decir que la posibilidad se da en el encuentro del hombre con el mundo y la búsqueda infinita de su sentido ${ }^{31}$. Sería imposible establecer una distinción entre realidad y ficción si no existieran ambos niveles de experiencia. Es la distancia y la cercanía de ambas lo que permite la interrelación y reconocimiento de las mismas. Y es la posibilidad la que, como estructura de la experiencia, contiene una modalidad vivencial que permite el estilo cognoscitivo de la ficción. Sin embargo, se ha de decir que el conocimiento, a través de ella alcanzado, puede ser un conocimiento universal desde el punto de vista vivencial en la medida en que lo que está en juego es la existencia de un hombre capaz de asumir el alma de otros, de traspasar las limitaciones de su propia corporalidad, asumiendo la carnalidad de una humanidad que nunca me ha sido, ni me fue, ajena y que no se halla sujeta a las contingencias de la facticidad, ya sean históricas, sociológicas, etc. En este sentido, pueden ser recordadas las palabras de Aristóteles cuando afirma que

«el historiador y el poeta no difieran entre sípor el hecho de que uno escribe en prosa y otro en verso; pues podrían versificarse las obras de Herodoto y no por ello serían menos historia de lo que son. La diferencia radica en el hecho de que uno narra lo que ha ocurrido y el otro lo que ha podido ocurrir. Por ello la poesía es más filosófica y elevada que la historia, pues la poesía canta más bien lo universal, y en cambio la bistoria lo particular» ${ }^{32}$.

Reformulando las consideraciones aristotélicas se podría decir que la historia o la ciencia pretenden desvelar los acontecimientos que acaecen o fácticos; sin embargo, la poesía, en tanto desvela lo universal, muestra no ya ámbitos

30 Si no, recuérdese a Husserl cuando decía que «toda agregación de nuevos caracteres noéticos o toda modificación de caracteres viejos, no solo constituye nuevos caracteres noemáticos, sino que eo ipso se constituyen para conciencia nuevos objetos existentes; a los caracteres noemáticos corresponden caracteres predicables en el objeto o sentido, como predicables reales y no tan solo modificados noemáticamente» (Husserl, E., Ideas relativas a una fenomenología pura y una filosofía fenomenológica, F.C.E., México/ Buenos Aires, 1985, pág. 253).

${ }^{31} \mathrm{Y}$ continuando con Havel se podría decir con sus palabras que «en efecto: una vida relativamente soportable en este mundo solo la puede proporcionar una especie de humanidad que esté orientada "más allá" de este mundo, que—con cada uno de sus "aqui" y "ahora"—se relacione con el infinito, el absoluto y la eternidad. Una orientación absoluta hacia el "aqui" y "ahora", por más soportable que sea, irremediablemente transforma aquel "aqui" y "ahora" en desolación y baldio ya acabo tiñéndolo con sangre» (Havel, V., op. cit., pág. 334).

32 Aristóteles, Poética, Bosch, Barcelona, 1987, pág. 35. 
modificados, sino todo un proceso de metamorfosis que pone de manifiesto la vinculación esencial entre el hombre y el mundo, así como las posibilidades simbólicas de mediación entre ellos. En este sentido, parece querer desplegar horizontes no tematizados pero que conforman la estructura de la experiencia posible. Además, en todo este proceso de metamorfosis, se somete la realidad empírica a un proceso de experimentación que proporcionaría la habilidad para hacer intuibles ciertas estructuras experienciales que desanudarían las grandes diferencias entre la realidad y la ficción. Por ello, parece interesante e importante recordar lo que Husserl denomina análisis intencional y que

«lleva sin duda, en ciertas direcciones temáticas de la atención, también a hacer divisiones, y en tanto es así puede seguir sirviendo la palabra; pero su obra doquiera peculiar es el descubrimiento de las potencialidades implíitas en las actualidades de la conciencia, mediante el cual se lleva a cabo en el respecto noemático de la "exhibición", la "iluminación" y eventualmente la "aclaración" de lo presunto por la conciencia, del sentido objetivo. El análisis intencional va guiado por el fundamental descubrimiento de que todo cogito, en cuanto conciencia, es en el más amplio sentido asunción de lo asumido por él, pero que esto, lo presunto, es en todo momento más (está presunto con un plus) de lo que en el momento está delante como "explicitamente" asumido»33.

Los análisis intencionales husserlianos trasladan la posible universalidad del conocimiento hacia un cogito que sufre una apertura de su conciencia hacia un horizonte no cerrado en la intuición de ningún factum. Por el contrario, la conciencia, centrada en un cogito, desvela una multiplicidad de posibilidades en la apertura de una intencionalidad que se traslada hacia un afuera infinito. Así pues, la universalidad mostrada por la poesía, o digamos por el arte, es el descubrimiento del horizonte como campo de posibilidades ${ }^{34}$ desplegado a través de tales análisis intencionales. De este modo,

«la estructura horizontal - afirma de nuevo Husserl—de toda intencionalidad impone, pues, al análisis y la descripción fenomenológicas un método totalmente nuevo, un método que entra en acción doquiera surgen la conciencia y el objeto, la asunción y el sentido, la realidad real y la ideal, la posibilidad, la necesidad, la mera apariencia, la verdad, pero también la experiencia, el juicio la evidencia, etc., como titulos de problemas trascendentales, y hay el deber de trabajarlos como auténticos problemas de "origen" subjetivon" 35 .

Se estará de acuerdo con esta aseveración si se toma en consideración que el ámbito de la fantasía se abre tras un cambio de actitud, si se acepta el pacto

${ }^{33}$ Husserl, E., Meditaciones cartesianas. Introducción a la fenomenologia, F.C.E., Madrid, 1985, pág. 95.

${ }^{34}$ Husserl, E., Experiencia y juicio, págs. 33-34.

35 Husserl, E., Meditaciones cartesianas, pág. 98. 
de incredulidad o, en terminología de Handke, se desexistencializa la realidad natural y la abre a una diversidad de realidades múltiples dada por el cambio de actitud que se da en la vida-que-experiencia-mundo (welterfaherendes leben) y que abre y muestra un sentido de posibilidad que enriquece y despliega los horizontes intencionales. Ahora bien, para que un mundo posible-intencional tenga una unidad, ya lo hemos dicho, es menester que no contenga ni contradicciones ni inconsistencias. No obstante, en el despliegue continuo de las metamorfosis y contaminaciones a las que se ve sometida la realidad en el universo de ficción, se ha de encontrar una estructura de la experiencia posible y una conexión, un hilo de enlace que hilvane la multiplicidad de experiencias que el hombre halla en su devenir existencial. Tal hilo no parece ser otro que la temporalidad y, utilizando una aseveración de Ricoeur, estaremos de acuerdo en que «el carácter común de la experiencia bumana, señalado, articulado y aclarado por el acto de narrar en todas sus formas, es su carácter temporal» ${ }^{36}$.

Si se ha mostrado una unidad que dé sentido a todo el proceso de variación de las realidades, ha sido para salvaguardar la conciencia de la locura a la que pudiera abocar. También salvar la posibilidad de la comunicación, pero, en cualquier caso, se ha de destacar el carácter de exposición que tal proceso contiene. No solo como exponer un sentido o una realidad, sino también como exponerse, entregarse a realidades donde la vida se pone en juego, donde los límites sufren una apertura y, en ocasiones, se pone en riesgo y se vulnera la mismidad de la conciencia. En este proceso de multiplicación de la realidad es donde la pasión por experimentar, por variar la realidad, muestra la iniciativa por encontrar en ella algo que, sin ser lo "esencial" al estilo husserliano, al menos, desvela un universal de reconocimiento que en la multiplicidad de metamorfosis a las que es sometida la realidad, surja como una estructura de la experiencia posible que dé acceso a la diversidad de figuras de alteridad abiertas. Recuérdese, en este sentido, las ya mencionadas variaciones eidéticas de Husserl, en las que se somete cualquier hecho fáctico a un proceso de variaciones a fin de encontrar en tal proceso una esencia que permanezca en tal cambio, una estructura invariable que dé sentido a todo el procedimiento. Sin entrar en la discusión teleológica husserliana, sí se ha incidido en páginas anteriores sobre la importancia que adquiere el movimiento de la posibilidad sobre la realidad de la fenomenología y en el ámbito de la novela como un otro de la realidad que se ve sometido a un juego de cambios continuos. De este modo, se muestra que la realidad se multiplica infinitamente en un proceso de búsqueda de las estructuras radicales que conforman todo mundo posible. En este sentido, pues, es procedente recordar las palabras de Husserl, en las que se afirma que

36 Ricoeur, P., «Narratividad, fenomenología y hermenéutica» en Horizontes del relato. Lecturas y conversaciones con Paul Ricoeur, Gabriel Aranzueque (Comp.), Cuaderno Gris, 2, Época III, Madrid, 1997, pág. 480. 
«la totalidad de las posibilidades libres en general es un reino de la inconexión, pues le falta la unidad de la conexión. Sin embargo, toda posibilidad entresacada de abi designa en él a la vez la idea de una totalidad de posibilidades coherentes y a esta totalidad le corresponde necesariamente un tiempo. Cada totalidad de este tipo define a un mundo» ${ }^{37}$.

Sin embargo, si se ha de dar fe a las aseveraciones husserlianas, se establecerá que la fantasía permite multiplicar y marcar diferencias sin repetición en la medida en que ningún mundo posible, así como ningún individuo posible e irreal, es intercambiable, repetible, sino más bien, por el contrario, "único" y abierto $^{38}$. Por otra parte, este carácter de abierto, que permite la multiplicación y la diferencia fundacional de los mundos posibles como variaciones de la fantasía, provoca uno de los caracteres más importantes de los mundos posibles, esto es, la incompletud. «Si la incompletud es una "deficiencia" lógica de los mundos ficcionales, es un factor importante de eficiencia estética» ${ }^{39}$. Tan importante como que permite aún más multiplicar la realidad ficcional en la medida en que abre la interpretación del lector a infinidad de ellas, multiplicando de este modo no solo la realidad sino las experiencias por ella producida. Se coincidirá con Henry James cuando asegura que

«la experiencia no es jamás limitada, ni termina nunca: es una inmensa sensibilidad, una especie de enorme telaraña de finisimos hilos sedosos suspendida en la cámara de la conciencia, que apresa en su tejido todas las partículas llevadas por el aires ${ }^{40}$.

La multiplicación generada por la fantasía concentra un horizonte de variaciones infinitas que están regidas por cierta estructura intencional que permite el encuentro y la representación de las intenciones humanas ${ }^{41}$. La recreación de la ficciones se constituye, pues, en la presentación de las diversas partículas que conforman el tejido de la experiencia, es decir, las variaciones resaltan y ocultan las diversas perspectivas que se producen entre los elementos que construyen todo mundo en la medida en que a partir de ellos se constituyen las estructuras de la realidad en base al concepto de posibilidad, desvelándose con ello toda la diversidad de realidades múltiples. En este sentido, si asumimos

37 Husserl, E., Experiencia y juicio, pág. 394.

${ }^{38} \mathrm{El}$ texto de Husserl continúa de la siguiente forma: «Pero dos mundos de este tipo carecen de conexión, sus "cosas", sus lugares, sus tiempos nada tienen que ver unos con otros; no tiene sentido preguntar si una cosa en este mundo posible y una cosa en aquel otros es o no es lo mismo» (ibid., pág. 394).

39 Dolezel, L., Possible Worlds and Literary Fictions, pág. 234.

40 James, H., El futuro de la novela, Escuela de letras, Madrid, 1994, pág. 28.

41 Para un acercamiento al problema de los mundos posibles desde una perspectiva psicológica remitimos Bruner, J., Realidad mental y mundos posibles. Los actos de la imaginación que dan sentido a la experiencia, Gedisa, Barcelona, 1988. En la medida en que como el propio Bruner afirma «el objeto de la narrativa son las vicisitudes de las intenciones humanas» (ibid., pág. 27). 
que toda narración ficticia gira en torno a unos acontecimientos imaginarios con personajes fingidos o no, utilizando un discurso narrativo mimético-imaginario que produce una realidad significativa, dobladora de la realidad empírica en la que se pone en juego una existencia ilusoria, también se asumirá que los mundos posibles-significativos desarrollan un movimiento desde las experiencias de una intención significativo-comunicativa de un autor o varios, hacia una intención receptora que, tras un pacto de credulidad o una modificación de la conciencia, desemboca en un mundo donde se desarrollan experiencias que le trasladan a una realidad diferencial a través de egos experimentales, además de proporcionar vivencias que de otro modo difícilmente aceptaría y asumiría. Así pues, las variaciones a las que se ve sometida la realidad y el propio sujeto envuelto en un desdoblamiento de su identidad, recabarán en la manifestación de aspectos ocultos de una realidad unívoca en su pragmaticidad, en definitiva, iluminando posibilidades oscurecidas. No obstante, la diferencia abierta entre los diversos mundos posibles conduce hacia su no repetición en la medida en que tales mundos contienen sus propios rasgos narrativos de manifestación, así como diversos personajes que se comportan con un carácter distinto dependiendo de la unidad intencional que los ha producido, esto es, no son repetitivos, sino únicos en su universo de ficción. Ahora bien, tal diferencialidad de los mundos posibles solo puede hacerse patente desde actos intencionales que ponen entre paréntesis la realidad de la vida cotidiana, la desconectan, la descarnalizan, pero la reterritorializan, por utilizar una expresión de Deleuze, en un universo de ficción donde, si no adquiere una carne determinada, sí al menos una unidad de acción que le hace ser un individuo determinado por un modo de ser desarrollado a través de su personalidad y, por tanto, irrepetible. Más aún, utilizando las reflexiones de Peter Handke, «la fantasía sería el eliminar fantaseando la corporalidad, de modo que la verdad apareciera en su multiplicidad, mostrándose quése debe hacer» ${ }^{42}$. Sin embargo, esta descarnalización de la que habla Handke (nosotros hablaremos de des-existencialización) contiene en sí misma una coherencia y consistencia que dona ilusión de realidad, así como posibilita la multiplicación del mundo o mundos. Por otra parte, esta des-existencialización, ofrecida por la ficción, permite permutar el conocimiento de la realidad por el conocimiento de la posibilidad, condición necesaria de todo ámbito ficcional, así como un acercamiento más profundo a una realidad que ya no vendría definida solo y exclusivamente por los parámetros que rigen el ámbito de la vida cotidiana, sino también por la traslación de las estructuras de la experiencia humana hacia las distintas posibilidades desarrolladas en los diversos ámbitos de sentido, presentando la relevancia de acontecimientos límites como, por ejemplo, la vida solitaria de un hombre en una isla perdida en la inmensidad del mar, o la soledad de un sujeto transformado en insecto abandonado en un 167.

${ }^{42}$ Handke, P., Historia del lápiz. Materiales sobre el presente, Península, Barcelona, 1992, pág. 
cuartucho, o el pesar del remordimiento tras el asesinato de una vieja usurera. Se puede entrever, pues, que el ámbito de la fantasía se configura como campo de posibilidades en que nos está permitido explorar de forma experimental las diversidades que se abren en el entrecruzamiento de las distintas realidades en las que se conforma el mundo en tanto ámbito cultural-significativo. En esta dinámica se adentra la subjetividad lectora cuando acepta embarcarse en cualquier aventura, ya sea recorrer los mares del sur con Conrad o adentrarse en el alma humana con Dostoyevski; acepta un proceso de descorporalización conducente hacia la posibilidad de habitar un mundo completamente distinto (o no) al que le ha tocado vivir en su facticidad, sometiéndose a circunstancias extrañas y adquiriendo con ello la posibilidad de encontrarse viviendo no ya como un ser en el mundo, sino como un ser-entre-mundos.

No está lejos, quizás, de esta idea el concepto de "descripción densa" que postula Geertz en su libro La interpretación de las culturas en la medida en que se plantea la posibilidad de investigar las diversas culturas como posibilidades humanas. Con este concepto intenta poner de manifiesto Geertz la infinidad de significaciones culturales en las que se conforma cualquier acontecimiento cultural que configura la "forma de vida" de un pueblo ${ }^{43}$. De este modo, pareciera que estas diversas significaciones culturales, que constituyen posibilidades de vida, desde los pigmeos hasta el hombre contemporáneo occidental, pasando por chinos, japoneses, etc., se configuran como posibilidades humanas abiertas en distintos universos existenciales que plantearían un marco de comprensión distinto y distante, además de requerimientos y soluciones diversas. De este modo, se ha de entender que la primera posibilidad abierta al sujeto es el Otro de carne y hueso, aquel que se presenta en cualquier proceso conversacional pero que, al mismo tiempo, se oculta tras tradiciones, costumbres, ideologías, que dificultan un diálogo entre ellas. Por ello Geertz pretende «encarar una antropología concebida como acto interpretativon. Así pues,

"hacer etnografía es como tratar de leer (en el sentido de "interpretar un texto") un manuscrito extranjero, borroso, plagado de elipsis, de incoherencias, de sospechosas enmiendas y de comentarios tendenciosos y además escrito, no en las grafias convencionales de representación sonora, sino en ejemplos volátiles de conducta modelada» ${ }^{4}$.

43 Afirma Geertz radicalmente, no sin un cierto guiño interpretativo, que «elaborar descripciones orientativas hacia el punto de vista del actor de los hechos relativos a un caudillo beréber, a un comerciante judio y a un militar francés en el Marruecos de 1912 constituye claramente un acto imaginativo, en modo alguno diferente de la elaboración de análogas descripciones de, digamos, las relaciones que tenían entre sí un médico de provincias francés, su boba y adúltera esposa y el fútil amante de la Francia del siglo XIX» (Geertz, C., La interpretación de las culturas, Gedisa, Barcelona, 1990, pág. 28). Por otra parte, para acceder a las vinculaciones que se establecen entre literatura y antropología véase Clifford, J., Dilemas de la cultura. Antropología, literatura y arte en la perspectiva posmoderna, Gedisa, Barcelona, 1995.

${ }^{44}$ Ibid., pág. 24. 
En este sentido, puede ser entendida en toda su extensión la aseveración casi tajante de Deleuze cuando afirma que el objetivo último de la literatura es «poner de manifiesto en el delirio de esta creación una salud, o esta invención de un pueblo, es decir, una posibilidad de vida» ${ }^{45}$. Entonces, si se ponen en comunicación la antropología y la literatura, se ofrece una pluralidad de posibilidades vitales que devienen en una multiplicidad y un marco de diferencias que solo podrían hacerse comunicables en la unidad de una conciencia que tiene la capacidad de donar sentido y unidad a las fluyentes diferencias. En este sentido, se mostraría que las distintas marcas del mapa existencial que nos abre cualquier relato ficcional ofrecen la posibilidad de reconocernos al mismo tiempo que extrañarnos; descubrirnos en una misma conciencia, quizás una conciencia trascendental, a la vez que extrañarnos en una existencia ajena, esto es, entrar en un orden de pertenencia particular pero, al mismo tiempo, desplazarse en la búsqueda de nuevas modalidades del existir. En este sentido, escribe Husserl que

\begin{abstract}
"fantasía es la conciencia caracterizada como actualización (Vergegenwärtigung) (reproducción). Sin duda existe en tiempo actualizado, pero éste remite necesariamente a un tiempo originariamente dado, no fantaseado, sino presentado. La actualización es lo opuesto al acto originariamente dador; ninguna representación puede "surgir" de ella. Esto significa que la fantasía no es una conciencia que pueda of recer una objetividad o un rasgo esencial y posible en una objetividad o un rasgo esencial y posible en una objetividad, como dado con ipseidad. En efecto, el no dar con ipseidad es, en rigor, la esencia de la fantasía. Inclusive el concepto de la fantasía no ha brotado de la fantasía, tenemos ciertamente que tomar fantasías; pero ello no significa todavia un darse» ${ }^{46}$.
\end{abstract}

Se concluirá, pues, que la única estructura capaz de donar ipseidad a un mundo posible no es más que la subjetividad como donadora de sentido, en la medida en que se puede considerar toda obra ficcional como el intento de abarcar el sentido con más densidad y condensación de lo habitual. El concepto de condensación determina una dimensión de homogeneidad y unidad; pero también la involucración de la vida-que-experiencia-mundos presentaría una multiplicidad, referida a la pluralidad de mundos, que estaría enfrentada a la homogeneidad y unicidad de tal condensación. No obstante, se ha de distinguir entre condensación y simultaneidad. Por condensación se entenderá una concentración de sentidos que en tal proceso de unión requiere un posterior despliegue para que las diversas significaciones se pongan de manifiesto. Esto es, la condensación significativa es la implicación de infinidad de sentidos en un solo o pocos signos que necesitan de otra experiencia para deshilvanar sus significaciones y donarles sentido. Por el contrario, la simultaneidad es la concentración actual y aleatoria de los objetos mundanos, su coexistencia

45 Deleuze, G., Crítica y clínica, Anagrama, Barcelona, 1996, pág. 16.

${ }^{46}$ Husserl, E., Problemas fundamentales de la fenomenología, pág. 93. 
espacio-temporal. Así, la temporalidad de la simultaneidad es la actualidad; en este sentido, la simultaneidad es cósica, pertenece al mundo. La condensación, al contrario, pertenece al ámbito de la obra, de las creaciones humanas. Es, por tanto, básicamente temporal en la medida en que requiere un despliegue, en este caso, significativo. El despliegue significativo solo puede ser realizado por una vida-que-experiencia-mundo. Este será el trabajo de una subjetividad lectora; descondensar/descodificar la significatividad de la obra. Para ello, las pausas que conforman una obra literaria establecen intersticios a través de los cuales la experiencia de un sujeto puede donar presencia a una vida-ficticia-queexperiencia-mundo. El trabajo de descondensación requiere tiempo, un devenir temporal que deshila la "no-existencia" de los entes ficcionales. En este sentido, afirma Magris que

«la novela es el género literario que representa al individuo en la prosa del mundo; el sujeto se siente extranjero en la vida, escindido entre su interioridad nostálgica y una realidad exterior indiferente e inconexa. La novela es a menudo la historia de un individuo que busca sentido inexistente, es la odisea de un engaño» ${ }^{47}$.

Si bien en estas páginas no se estará de acuerdo con el carácter pesimista y nihilista de las palabras de Magris, sí se quisiera recoger como elemento primordial la búsqueda de sentidos que escinda y altere el mundo de modo radical, tan es así que pudieran crearse y constituirse significaciones mundanas capaces de afirmar otros mundos posibles en los que desarrollar una subjetividad constituyente de sentido en y a través de sus experiencias. Este desarrollo experiencial es un factor significativo de primer orden en la experimentación de nuevos caminos existenciales humanos que abra la existencia mundanofáctica a nuevos modos de existir que deban ser recorridos por una subjetividad, en este caso, ficticio-ideal que se involucre en tales mundos posibles. Dicha introducción de la subjetividad lectora en los mundos posibles solo puede acontecer si el texto está abierto, si muestra vacíos en los que pudiera entrar la vida-que-experiencia-mundo-lectora. Dichos vacíos son indispensables y condición necesaria para el carácter polisémico de toda obra literaria, además de constituir la obra por acumulación significativa, conformándola desde cierto abigarramiento que conllevaría la imposibilidad de la comprensión de la propia obra literaria en la medida en que sería una obra cerrada no trascendente. La trascendencia de dicha obra no puede venir desde otro lugar que no sea la involucración de otro que done significaciones que plenifiquen y enriquezcan el horizonte de comprensión de la misma, así como, ofreciéndose desde otro mundo posible, que vivifique experiencialmente la plenitud polisémica de la obra. Esto es, done una interpretación posible a la obra, signifique, desde una

${ }^{47}$ Magris, Cl., El anillo de Clarisse. Tradición y nibilismo en la literatura moderna, Península, Barcelona, 1993, pág. 24. 
perspectiva, la apertura del mundo posible estructurado por la obra literaria. En este sentido, pues, la alteridad de los mundos posibles se transforma en una estructura apriórica que conforma y configura la estructura textual. Es el Otro, por tanto, como estructura experiencial, el que permite vivificar las experiencias expresadas en las palabras y pausas que constituyen un texto, el que da sentido a la obra de arte o literaria, en este caso. Podemos decir con palabras de Octavio Paz que «el poema devora al poeta», lo devora en la medida en que deja hablar al oído que escucha ya que es el que da vida a la escritura. Es el que puede donar presencia a las ausencias que conforman las estructuras significativas que constituyen la obra literaria. Por tanto, el Otro se configura como una estructura esencial en la constitución de la obra, ya sea el lector real, ya aquel contenido en la propia estructura generativa de la obra de ficción, ya el propio autor. De este modo, es la apertura esencial del yo el que permite, en su exposición, abrir el campo de fenomenalidad. La apertura estructural del yo autoriza el tránsito entre mundos en los que la subjetividad habita y constituye. Esto no debe entenderse como un ejercicio de libertad, sino al contrario es un momento de involucración en un mundo donde las reglas y el estilo cognoscitivo vienen dados y se asumen en la participación de las estructuras significativas abiertas; es un momento de vulnerabilidad desde donde la subjetividad se deja llevar hasta las experiencias mentadas. De este modo, la subjetividad se constituye en el desplazamiento de la obra abierta al otro, rememorando un no-lugar necesario para la comprensión de cualquier obra humana. Este no-lugar, este espacio vacío, se presenta como la única posibilidad que rompe las estructuras de delimitación de toda obra humana. En este espacio de indeterminación, el sujeto se halla expuesto a las diversas experiencias allí presentadas. A ellas atiende y en ellas se muestra involucrado como lugar de experiencias desde las que acceder a un nuevo ámbito de experiencia. De este modo, la subjetividad se constituye desde el exterior o, al menos, desde el intersticio abierto en la constitución de la obra. La lectura se muestra como el lugar donde la experiencia asume la totalidad de su responsabilidad hacia aquello fuera de ella y en su propio interior y la obra en su propia constitución como algo fuera de cualquier objetivación. Se muestra como aquello que siempre puede dar más de sí en la medida en que la lectura abre infinidad de campos de interpretación. Desde ésta se nos ofrece esa capacidad para abrir y permanecer en ese campo de indeterminación que muestra la exposición siempre presente del ser humano. Su potencialidad para abrir nuevos mundos y su efectualidad para construir barreras. Podríamos recuperar de algún modo la afirmación de Levinas cuando afirma que

«el Otro en el Mismo de la subjetividad es la inquietud del Mismo inquieto por el Otro. Ni la correlación de la intencionalidad, ni siquiera la del diálogo atestiguan la esencia en su reciprocidad esencials ${ }^{48}$.

${ }^{48}$ Levinas, E., De otro modo que ser, o más allá de la esencia, Sígueme, Salamanca, 1987, pág. 72. 
Podríamos pensar que en la interioridad del humano hay una grieta, una indisposición esencial, desde la cual se presentaría la exposición como estructura experiencial fundamental para la comprensión de lo humano. No es una nada desde la cual el hombre crearía sus mundos, al contrario, es una exposición hacia un afuera constitutiva y en tal relación mostraría la capacidad constitutiva de la conciencia humana. Afirma en esta dirección Pico della Mirandola que Dios dio «al hombre una forma indeterminada, lo sitúo en el centro del mundo y le habló así: (...) Tendrás y poseerás por tu decisión y elección propia aquel puesto, aquella imagen y aquellas tareas que tú quieras.... ${ }^{49}$. No obstante, no quisiéramos reivindicar un concepto de libertad moderno desde el cual el hombre modificaría el entorno en el que habita y a sí mismo en ese proceso sin encontrar fuera nada no humano. Al contrario, el ser humano en su exposición a las estructuras de habitabilidad de los mundos constituidos por él mismo se plantea la búsqueda de aquello que lo hace ser el que es o podría ser. Se rastrea desde las posibilidades abiertas por la indeterminación de la obra literaria una nueva dimensión de la subjetividad, la del testigo. Desde la presencia ineludible de la obra, la conciencia humana queda abierta a nuevas dimensiones que sobrevienen y constituyen dirigiendo la experiencia que ha de ser completada desde la intersubjetividad tanto del autor como del lector ${ }^{50}$. Si la obra toma un estatus ontológico propio, la figura de aquel que se adentra en sus páginas se presenta como un testigo, como una figura dominada por las experiencias expuestas. El sujeto expuesto al dominio de la obra abre su conciencia y amplía el campo de fenomenalidad en la desmesura de ausencias abiertas en la propia obra. La intercomunidad creada en la lectura supura la experiencia del que en ella se adentra ya que esta tiene un sí mismo dado desde el cual se asiste a una serie de experiencias en las que adentrarse y convivir con ellas. Cuando decíamos que la subjetividad se transformaba en un ser-entre-mundos, nos referíamos a experiencia en la que el ser humano asiste a una infinidad de estructuras en las que desarrollarse y sobre las que no tiene ninguna voluntariedad. El pacto de incredulidad es esta alteración de la conciencia que permite al sujeto-lector asistir y dejarse llevar, conducirse por las líneas trazadas en la obra. Esta alteración permite que la conciencia se entregue a una experiencia que estalla en un devenir que metamorfosea las estructuras de la cotidianidad y nos aproxima a una serie de posibilidades ignotas desde

49 Pico della Mirandola, G., «Discurso sobre la dignidad del hombre» en Humanismo y Renacimiento, Alianza, Madrid, 1986, pág. 123.

50 «La obra literaria, en cuanto tal, es una formación puramente intencional que tiene la fuente de su ser en actos de conciencia creativos de su autor, y cuyo fundamento físico está en el texto escrito o en otro medio físico de posible reproducción (como por ejemplo una cinta magnética). En virtud del estrato dual de su lenguaje, la obra es accesible intersubjetivamente y reproducible, de manera que se convierte en un objeto intencional intersubjetivo, relativo a una comunidad de lectores. De este modo no es un fenómeno psicológico, sino que trasciende todas la experiencias de conciencia, tanto del autor como del lecton» (Ingarden, R., "Concreción y reconstrucción», en Teoría de la novela. Antología de textos de siglo $X X$, pág. 36). 
las cuales el mundo se abre y permite la reconciliación con un mundo siempre desconocido. En este sentido, afirma Marion que

«este efecto no se produce bajo el modo del objeto, ni se constituye o reconstituye bajo el modo del ente: el efecto se da. El cuadro (y por él cualquier otro fenómeno en grados diferentes según cada caso) se reduce a su fenomenicidad última en tanto que da su efecto. Aparece en tanto que dado en el efecto que se da. Asi se define la esencial invisibilidad del cuadro, ante la cual podemos pasar porque no hay nada que ver, ni objetivo ni óntico: al final, de todo ente reducido solo queda el efecto, tal y como lo visible se da en él, se reduce a lo dado. El cuadro no es visible, sino que visibiliza; visibiliza en un gesto que permanece pues, por definición, invisible-el efecto, el surgimiento, el despunte del darse. Darse exige reducirse - reconducir - a ese efecto invisible que es lo unico que visibiliza. Solo el fenómeno reducido a lo dado surge el efector ${ }^{51}$.

La presentación del texto, si atendemos a las palabras de Marion, se da de un modo efectual, sin conocer las causas de su donación, ni tampoco los elementos estructurales que permiten su presentación, tan solo la posibilidad de adentrarse en el universo abierto desde sus líneas y la virtualidad de acceder a las experiencias que desde ellas se irradian hacia la totalidad de la intercomunidad de lectores.

Elefecto de la obra viene marcado, o mejor, desmarcado, por la indeterminación y los espacios vacíos ya comentados. Desde ellos, la subjetividad lectora se halla involucrada en una vorágine de experiencias significativas donde la realidad presentada absorbe a la propia subjetividad y la traslada hacia lugares habitados e inhabitables pero, en cualquier caso, a espacios donde se muestra lo que es, fue o podría ser. Se recupera en un proceso de experimentación donde las líneas de comprensión se difuminan y su propia identidad se trastorna ${ }^{52}$. La aparición de lo dado reconduce a la subjetividad hacia un lugar pasivo desde el cual solo queda recibir los acontecimientos acaecidos en los diversos mundos proyectados. No se trata ya de un ego constituyente, sino del receptor de la multiplicidad de lo dado en el texto; ese receptor no constituye ningún objeto unificado por concepto, sino que se deja asignar tantos "sentimientos" venidos

${ }^{51}$ Marion, J-L., Siendo dado. Ensayo para una fenomenología de la donación, Síntesis, Madrid, 2008, pág. 103.

52 Afirma Iser, en este sentido, que «tanto aquí como alli, la carencia es un acicate, esto es, los grados de indeterminación que se encuentran en la asimetría del texto y el lector comparten con la contingencia o con el no-cosa de la interacción interhumana la función de ser constituyentes de la comunicación. Los grados de indeterminación de la asimetría, de la contingencia y del no-cosa son, por tanto, solo diversas formas de un vacio constitutivo, mediante el que se funda las relaciones de interacción. Este vacio no ha sido dado con antelación de las relaciones mencionadas, en cuanto un fundamento ontológico, sino que se configura y varía mediante el desequilibrio dominante en la interacción diádica o en la asimetría entre texto y lector. El equilibrio solo se recupera mediante la supresión de la carencia, por lo que el vacio constitutivo constantemente es ocupado por proyecciones» (Iser, W., El acto de leer. Teoría del efecto estético, Madrid, Taurus, 1987, pág. 260). 
como le pida la rapsodia de lo diverso que se está mostrando. La subjetividad se presta a la llamada dada desde las experiencias abiertas en las indeterminaciones propuestas por el texto. Esta llamada se despierta desde la grieta abierta en la condensación significativa del texto y en la que tal subjetividad pasiva muestra las dificultades para garantizar su identidad y entra en un proceso de desfiguración por asumir las nuevas categorías y experiencias dadas. La pasividad, la atención a las experiencias propuestas, asume las nuevas experimentaciones y las ignotas posibilidades desde las que poder reconfigurarse y asirse desde nuevas perspectivas mundanas. Por tanto, la subjetividad, desde la propuesta textual, ha de reconfigurar continuamente sus estructuras de competencia existencial en la medida en que la atención hacia aquello dado muestra una nueva forma de existir, una nueva forma de vivir; en definitiva, alertar sobre nuevas posibilidades vitales. Transformar, por tanto, sus propias visiones se muestra como algo esencial en el adentramiento de un mundo dado y asumido desde su propio aparecer. La pasividad de la subjetividad establece un compromiso con el aparecer de lo dado en la realidad literaria, constituyendo una relación de convicción-dentro del pacto de incredulidad - con la llamada de la realidad dada en las páginas presentadas. Tal convicción dentro del pacto de incredulidad es la estructura necesaria para la comprensión de la realidad dada. Permite descodificar las palabras y "vivir" las experiencias expuestas. De este modo, el sujeto lector está expuesto y abierto a todas las experiencias dadas en la realidad y, por tanto, con su propia identidad desplazada, asume diversidad de las mismas en el deseo de ser otro, en la medida en que, como afirma Levinas, «la sensibilidad es la exposición al otro» ${ }^{53}$. En este sentido, podríamos interpretar esta idea de Levinas como la capacidad de la subjetividad para transformar el lenguaje en experiencia a través de la exposición a los acontecimientos acaecidos en las líneas de interpretación de cualquier texto ficticio. Este desplazamiento de la identidad podría hacernos pensar en una no-identidad o, mejor, un devenir en una diversidad de figuras iniciadas por el deseo de ser otro. De este modo, uno de los elementos constituyentes de tal subjetividad es su capacidad para metamorfosearse en el desplazamiento de la diversidad de estructuras constituyentes de los ámbitos de sentido constituidos desde las significaciones abiertas a través de los textos. En este sentido, la subjetividad, que podríamos llamar transversal, calibra distancias en el alejamiento y extrañamiento que produce en los objetos-estructurasexteriores a través de un proceso de inconveniencia, como encrucijada, con la potencialidad de relanzar sus propias estructuras experienciales a partir de los objetos hacia la exploración de tales organizaciones. Los objetos entrarían en la actividad de la conciencia como un proceso de exploración continua en la que se configuraría la propia subjetividad en un intento de entenderse a sí misma, si bien esa comprensión no vendría dada desde un extrañamiento del mundo, sino que este se establecería como su correlato, a partir del cual se pondrían las bases

53 Levinas, E., De otro modo que ser, o más allá de la esencia, pág. 133. 
para dirimir las distancias, explorarlas, alcanzar los límites y trazarlos. Así pues, en palabras de Zemelman, podemos decir que el

«sujeto fundador y activo que buscamos rescatar puede romper con lo evidente porque anima las formas del lenguaje. Es el que resiste la inercia y el que atraviesa hacia lo inédito en la búsqueda de nuevas significaciones, y que, por lo mismo, necesita de un lenguaje abierto a lo nuevo. Es el lenguaje de la mente utópica cuyo contenido es la incorporación de lo constituyente, en vez de quedarse atrapado en lo ya producido. El sujeto cuyo movimiento interno está inspirado por la conciencia del darse incesante del mundor ${ }^{54}$.

No permanecer, por tanto, en las exteriorizaciones establecidas, donde el sentido humano quedará desplazado, cosificado y, por ello, deshumanizado, sino remontarse hacia el origen de sentido de toda subjetividad constituyente. De este modo, se destacaría un sí mismo que no quede enclaustrado en todo aquello que lo rodea sino en la apertura de las posibilidades abiertas en el proceso de creación y comprensión de las estructuras significativas en las que se transforma el mundo.

Desde esta perspectiva, se establece, pues, una identidad como un valor relativo dentro del ámbito de la ficción y, desplazada, desde el adentramiento en los mundos ficticios. La identidad se transforma en ipseidad, esto es, en una subjetividad que se va reconstituyendo desde el tránsito y devenir en la fantasía. La ipseidad se muestra como una estructura temporal permitiendo discurrir y devenir hacia las diversas realidades; podríamos decir que se mueve en los intersticios, en lugares de tránsito o, por utilizar una expresión de Auge, nolugares. La conciencia se transforma en un lugar de tránsito cuya estructura fundamental es el tiempo. Este se muestra como el elemento constituyente de la posibilidad de una subjetividad, reconstituyéndose en el proceso de creación de distintos lugares donde el hombre pudiera habitar.

Desde esta perspectiva, pues, la subjetividad se mostrará como anárquica y vulnerable, pero no solo en su ser para el otro sino también en su constitución, en la medida en que tiene su origen desplazado hacia la exterioridad dada en la llamada textual. En este sentido, la estructura de la subjetividad se habrá de destacar desde su actividad lingüística y desde su capacidad para establecerse como origen de la misma. Ahora bien, no se pretende tanto destacar tanto la importancia de la proximidad, base para cualquier tipo de comunicación, cuanto establecer un lenguaje que pueda abrirse a tal proximidad. Se quisiera asumir un lenguaje con la suficiente potencia como para recorrer la distancia abierta desde una proximidad que, en tanto apertura de la mismidad, relanza a la subjetividad hacia una multidimensionalidad significativa calibrada por un lenguaje capaz de crear nuevos ángulos, asumiendo un acercamiento al mundo y los otros; además,

54 Zemelman, H., Sujeto: existencia y potencia, Anthropos/CRIM, Barcelona, 1998, pág. 49. 
tal lenguaje ha de despejar la distancia con respecto al otros desde la instalación y el emplazamiento de la subjetividad en el centro de su existencia, abierta hacia lo inédito y expuesta al misterio del mundo. Se podría recuperar, en este sentido, las palabras de Merleau-Ponty, cuando afirma que el lenguaje

«no dice nunca nada, lo que hace es mostrar una gama de gestos que presentan entre sí diferencias lo suficientemente claras como para que el comportamiento del lenguaje, a medida que se repite, se implica y se confirma a si mismo, nos proporcione de manera irrecusable la traza y los contornos de un universo de sentidor ${ }^{55}$.

El lenguaje no se encontrará, pues, determinado solo por los signos, sino también por aquello que se muestra entre ellos. Las pausas se tornan un elemento esencial en la posibilidad de donar sentidos y crear significaciones, además de autorizar a la subjetividad a introducirse en lo dicho e instalarse existencialmente en ello. Pausas, hilos de silencio, vacíos existenciales, en los que se muestra la posibilidad de recuperarse a través de la donación de sentido en la que se constituye la subjetividad. Tal donación de sentido solo es posible desde el paréntesis abierto por el vacío intersticial del intervalo lingüístico, a través del cual se sitúa una subjetividad—-transversal—que en su transitividad se encuentra capacitada para introducir, a partir de sí, una negación que abra dicha estructura lingüística a ámbitos de conocimiento ignotos y a través de los cuales se desvele un conocimiento de provincias de significado no tematizadas, apenas comunicativas, pero que tienden hacia virtualidades que trascienden hacia el no-ser ${ }^{56}$.

Ahora bien, este no-ser es la distancia que la subjetividad debe tomar en el proceso de recuperación en la medida en que, como ya hemos apuntado más arriba, la subjetividad es un no-lugar recuperado; no-lugar en virtud de su transitividad, de su transversalidad, de su capacidad para abrir espacios a partir de su actividad expresiva, de su constitución y donación de sentido; también de recuperación desde la puesta entre paréntesis que desexistencializa todo aquello que desde el ámbito de las vivencias se torna correlato de conciencia. Así pues, afirma Benoist que

«es precisamente el ser "en ninguna parte" del ego en el seno mismo de la vivencia lo que lo preserva contra la suspensión de la existencia que afectaría a tal o cual

55 Merleau-Ponty, M., La prosa del mundo, Taurus, Madrid, 1971, pág. 63.

${ }^{56}$ En este sentido, el lenguaje podría ser descrito como la ciudad Octavia, ciudad telaraña. En ella, como bien describe Calvino, hay «un precipicio entre dos montañas abruptas: la ciudad está en el vacio, atada a las dos crestas por cuerdas y cadenas y pasarelas. Uno camina por los travesaños de madera, cuidando de no poner el pie en los intersticios, o se aferra a las mallas de una red de cáñamo. Abajo no hay nada en cientos y cientos de metros: pasa alguna nube; se entrevé más abajo el fondo del despeñadero. Esta es la base de la ciudad: una red que sirve para pasar y para sostener. (...). Suspendida en el abismo, la vida de los habitantes de Octavia es menos incierta que en otras ciudades. Saben que la resistencia de la red tiene un límite» (Calvino, I., Las ciudades invisibles, Siruela, Madrid, 1998, pág. 89). 
vivencia. La egoicidad de la vivencia puede por ello manifestarse al nivel de la vivencia en tanto que tal, independientemente de la existencia de tal o cual vivencia, es decir, al nivel de la "conciencia pura" ${ }^{57}$.

La subjetividad se transforma en una especie de atractor de todo aquello que en torno suyo gira y a través de lo cual adquiere una nueva dimensión. No obstante, y al mismo tiempo, en la medida en que es un vacío transido por los más diversos mundos, esta, la subjetividad, debe recorrer aquello que entra en su ámbito expresivo, si quiere ser recuperada y comprendida. La subjetividad se torna en fuente de sentido, corriendo el riesgo de abismarse en el sin-sentido si no puede ser recuperada a partir y a través de lo dicho. Así pues, la subjetividad-transversal-se encuentra en un continuo trasiego en la recuperación y reconfiguración de aquello que pudiera constituirla. Esta toma de distancia, búsqueda incesante, será la base posible para nuestra comprensión de la subjetividad como ipseidad, esto es, como una subjetividad recuperada, en la medida en que ha recorrido caminos expresivos a través de los cuales encuentra aquello que pudiera donarle un sentido determinado. De esta manera, la subjetividad narrada solo puede venir dada mediante el relato como «guardián del tiempo en la medida en que no existiría tiempo pensado si no fuera narrados ${ }^{5}$.

Para terminar quisiéramos recordar el comienzo de estas páginas, el eco de la noticia del Mars-One, un espacio tecnológicamente transformado en un lugar inhóspito donde el ser humano pudiera desarrollar una vida cotidiana enclaustrada en un habitáculo acondicionado para la posibilidad de crear una atmósfera habitable. Ciertamente, tal acontecimiento se podrá llevar cabo y, aún, habrá personas con la osadía necesaria para adentrarse en tal experimento. Por otra parte, hemos de entender que tal acontecimiento mediático se presenta como una llamada sobre la soberbia del conocimiento humano y la inmensidad virtual de su poder. También podríamos pensar que exponer al ser humano en tal atmósfera nos podría proporcionar algún conocimiento sobre el comportamiento del hombre y sus potencialidades de adaptación a diversos entornos, e incluso a la soledad más absoluta. Por otra parte, no debemos olvidar el entretenimiento que produce observar a diversos tipos humanos interactuando entre ellos.

Pero también, se podría comprender tal hecho con una imagen quizás no muy afortunada aunque clarividente: Mars-One es la jaula con canario que colgaban los mineros en los túneles para comprobar la benignidad del aire: cuando éste era irrespirable, el pájaro moría y aquellos-los mineros-comprendían la imposibilidad de continuar en el interior de la mina; no era necesario permanecer.

57 Benoist, J., Egología y donación, pág. 113.

${ }^{58}$ Ricoeur, P., Tiempo y narración. Tomo III. El tiempo narrado, Siglo XXI, Madrid, 1996, pág. 991. 


\section{BIBLIOGRAFÍA}

AAVV. 1986. Humanismo y renacimiento. Madrid: Alianza.

Aranzueque, G. (comp). 1997. Horizontes del relato. Lecturas y conversaciones con Paul Ricoeur. Madrid: Cuaderno Gris, 2, Época III.

Aristóteles. 1970. Política. Madrid: Instituto de Estudios Políticos.

Aristóteles. 1987. Poética. Barcelona: Bosch.

Bachelard, G. 1991.La poética del espacio. Buenos Aires: F.C.E.

Benedetti. M. 1990.La realidad y la palabra. Barcelona: Destino.

Benoist, J. 1995.“Egología y donación: Primera aproximación a la cuestión de la presencia”. Anuario filosófico 28:109-141.

Blumenberg, H. 2007. Tiempo de vida, tiempo de mundo. Valencia: Pre-Textos.

BRUNER, J. 1988. Realidad mental y mundos posibles. Los actos de la imaginación que dan sentido a la experiencia. Barcelona: Gedisa.

Calvino, I. 1998. Las ciudades invisibles. Madrid: Siruela.

Cencillo Ramírez, J.L. 1978. El hombre, noción científica. Madrid: Pirámide.

Clifford, J. 1995. Dilemas de la cultura. Antropología, literatura y arte en la perspectiva postmoderna. Barcelona: Gedisa.

Deleuze, G. 1996. Crítica y clínica. Barcelona: Anagrama.

Gadamer, H-G. 1984. Verdad y método. Salamanca: Sígueme.

Geertz, C. 1990. La interpretación de las culturas. Barcelona: Gedisa.

Goodman, N. 1990. Maneras de hacer mundos. Madrid: Visor.

Habermas, J. 1988. Teoría de la acción comunicativa. Racionalidad de acción y racionalización social. Madrid: Taurus.

Handke, P. 1992. Historia del lápiz. Materiales sobre el presente. Barcelona: Península.

Havel, V.1990. Cartas a Olga. Barcelona: Versal.

HeIdegger, M. 1987. El ser y el tiempo. Madrid: F.C.E.

Husserl, E. 1980. Experiencia y juicio. Investigaciones acerca de la genealogía de la lógica. México: U.N.A.M.

HusserL, E. 1985. Ideas relativas a una fenomenología pura y una filosofía fenomenológica. México-Buenos Aires: F.C.E.

Husserl, E. 1985. Meditaciones metafísicas. Introducción a la fenomenología. Madrid: F.C.E.

Husserl, E. 1994. Problemas fundamentales de la fenomenología. Madrid: Alianza.

Iser, W. 1987. El acto de leer. Teoría del efecto estético. Madrid: Taurus.

James, H. 1994. El futuro de la novela. Madrid: Escuela de letras.

Kundera, M. 1987. El arte de la novela. Barcelona: Tusquets.

Levinas, E. 1987. De otro modo que ser, o más allá de la esencia. Salamanca: Sígueme.

Magris, C. 1993. El anillo de Clarisse. Tradición y nibilismo en la literatura moderna. Barcelona: Península.

Marion,J.L. 2008. Siendo dado. Ensayo sobre una fenomenología de la donación. Barcelona: Síntesis.

Martínez Bonati, F. 1992. La ficción narrativa (Su lógica y ontología). Murcia: Universidad de Murcia. 
Merleau-Ponty, M. 1971. La prosa del mundo. Madrid: Taurus.

Merleau-Ponty, M. 1975. Fenomenología de la percepción. Barcelona: Península.

Mukarovsky, J. 1977. Escritos de estética y semiótica del arte. Barcelona: Gustavo Gili.

MusiL, R. 1983. El hombre sin atributos. Barcelona: Seix Barral.

Ortega y Gasset, J. 1988. El hombre y la gente. Madrid: Alianza/Revista de Occidente.

Ricoeur, P. 1987. Tiempo y narración. Madrid: Cristiandad.

SÁbato, E. 1979. El escritor y sus fantasmas. Barcelona-Caracas-México: Seix Barral.

Sснӥтz, A. 1974. El problema de la realidad social. Buenos Aires: Amorrortu.

Sloterdijk, P. 2003. Esferas I. Burbujas. Madrid: Siruela.

SLOterdijK, P. 2004. Esferas II . Globos. Madrid: Siruela.

Sullá, E. (ed.). 1996. Teoría de la novela. Antología de textos del siglo XX. Barcelona: Crítica.

Warning, R. 1989. Estética de la recepción. Madrid: Visor.

Zemelman, H. 1998. Sujeto: existencia y potencia. Barcelona: Anthropos/CRIM. 